\title{
Augmenting Tertiary Students' Soft Skills Via Multiple Intelligences Instructional Approach: Literature Courses in Focus
}

\author{
El Sherief Eman \\ Prince Sultan University, Riyadh, Saudi Arabia \\ E-mail: eelsherief@psu.edu.sa
}

Received: 13-10-2016

Published: 01-03-2017
Accepted: 13-12-2016

doi:10.7575/aiac.ijalel.v.6n.2p.230
Advance Access Published: January 2017

URL: http://dx.doi.org/10.7575/aiac.ijalel.v.6n.2p.230

\begin{abstract}
The second half of the twentieth century is a witness to an unprecedentedly soaring increase in the number of students joining the arena of higher education(UNESCO,2001). Currently, the number of students at Saudi universities and colleges exceeds one million vis-à-vis 7000 in 1970(Royal Embassy of Saudi Arabia, Washington). Such enormous body of learners in higher education is per se diverse enough to embrace distinct learning styles, assorted repertoire of backgrounds, prior knowledge, experiences, and perspectives; at this juncture, they presumably share common aspiration which is hooking a compatible post in the labor market upon graduation, and to subsequently be capable of acting competently in a scrupulously competitive workplace environment. Bunch of potentialities and skills are patently vital for a graduate to reach such a prospect. Such bunch of skills in a conventional undergraduate paradigm of education were given no heed, being rather postponed to the post-graduation phase. The current Paper postulated tremendous merits of deploying the Multiple Intelligences theory as a project-based approach, within literature classes in higher education; a strategy geared towards reigniting students' engagement, nurturing their critical thinking capabilities, sustaining their individualistic dispositions, molding them as inquiry-seekers, and ending up engendering life-long, autonomous learners, well-armed with the substantial skills for traversing the rigorous competition in future labor market.
\end{abstract}

Keywords: Multiple intelligences, teaching Literature, motivation, autonomous learning, critical thinking.

\section{Introduction}

The second half of the twentieth century is a witness to an unprecedentedly soaring increase in the number of students joining the arena of higher education(UNESCO,2001). Currently, the number of students at Saudi universities and colleges exceeds one million in contrast to 7000 in 1970(Royal Embassy of Saudi Arabia, Washington). Such enormous body of learners in higher education is per se diverse enough to embrace distinct learning styles, diverse repertoire of backgrounds, prior knowledge, experiences, and perspectives; at this juncture, they presumably share common aspiration which is hooking a compatible post in the labor market upon graduation, and to subsequently be liable to act competently in a scrupulously competitive workplace environment. Bunch of potentialities and skills are indispensable for a graduate to gain a suitable job opportunity, which in a conventional undergraduate paradigm of education were given no heed, being rather postponed to the post-graduation phase. Nonetheless, with the escalating number of higher education students worldwide, more active strategies of learning were launched to refute the classical one-way transmission of knowledge approach, by means of which the learner adopts a passive role in acquiring knowledge.

With the escalating number of higher education students worldwide, more active array of learning strategies were launched to refute the classical one-way transmission of knowledge approach, by means of which the learner adopts a passive role in acquiring knowledge. The epitome of such avalanche of current cognitive theories was active learning. Active learning encompasses a vast spectrum of models as the peer-assisted technique, experiential learning, collaborative learning, the constructivist model, games-based learning, project-based learning, situated learning, flipped learning, and problem-based learning. Hamdam et al.(2013) and Bishop and Verleger(2013) manifested the spectacular efficacy of such strategies in engendering autonomous learners, able to search for knowledge instead of just acquiring knowledge. Oermann (2004) asserted that "active learning fosters critical thinking because students can explore alternate perspectives, examine different decisions that might be possible in a situation, analyze and weigh consequences of those decisions, and arrive at reasoned judgments"(p.1). Tippins, Tobin, and Hook(1993), on the other hand, evinced that the constructivist approach is: "an active process in which learners construct knowledge in a way that makes personal sense. And it is a subjective process, as learners draw on their own background experiences to make sense"(p.223). In such active process, the learning process started to take place a student-centered process, whilst the teacher is never exempted from the scene, but is more likely to act as a mere facilitator of knowledge. 


\section{Multiple Intelligences Theory}

It's undeniably perilous for learners to be confined within sterile curriculum-based models of learning, the premise of which are merely the logical/mathematical and verbal/linguistic intelligences, upon which the learner is being assessed. The matter that dragged massive amounts of remarkably talented students, with diverse other intelligences, to be underestimated, frustrated, de-motivated, and frequently marginalized by the classical forms of learning(Campbell,1996). In this connection, In lieu of laying the blame on the educational institutions, incapable of evincing serious commitment to ongoing professional development in order to update their teaching pedagogies, to deepen students 'engagement, students are to blame for the lack of motivation and the inadequate capacity of achieving with regards to the verbal and logical intelligences. "Learning is still widely viewed as a student and elementary/secondary school problem. Either students come to college with the skills and motivation to learn or they do not"(Lazerson et al., 2000,p.4).This would undeniably unravel the main reason beyond the overt de-motivation lecturers might witness among their students.

Discerning the individual needs and diversity of learning styles seems crucial to enhancing motivation and proved indispensable to the relentless process of quality assurance and constant progress of any educational institution(Felder\&Brent,2005, pp57-72). Those substantial demands have to be an integral pillar of any university mission statement, aligning in turn with the mission statement of each program and the set of CLOs for all program courses. Over the latter half of the twentieth century, cognitive theorists corroborated that the learning process, in a modern and patently digital era, should intrinsically be student-centered, and thus learners should be assigned a more active role in learnino that would incescantly foster their skills as autonomous learners

\section{Howard Gardner's Multiple Intelligences}

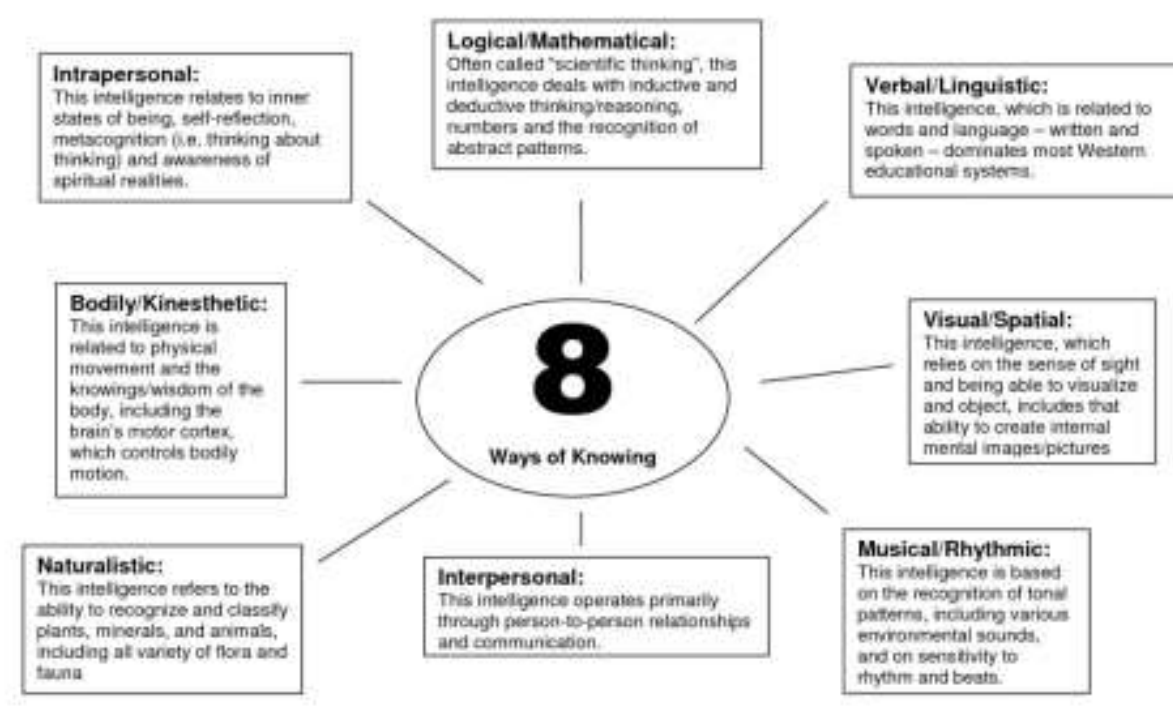

hrsplinwaw.education-world comva_curricurno54.shtmi
), culminated in who served via icus on linguistic ite being a novel that intelligence re, 1938). MI has iginate from the lve problems or (Gardner,1993). snted, while they Iusical/rhythmic, ords g. thm and tone.

and observation

Gardner refutably posited that every individual possesses variable types of intelligences not merely one as prior theorists hypothesized. Gardner went further to affirm that the type of intelligence an individual may possess predetermines various aspects of his/her life, among which the preferred learning style is prominent(Chapman, 2009). Not all of us learn the same way or are liable to create the same product. All human beings prove to possess all types of intelligences in varying percentages. Each type of intelligence is to be located in a certain area of the brain, acting on its own or alternatively tending to interact with other types to eventually engender a certain product(Gardner, 2004). The majority of people display multiple intelligences not merely one. According to Gardner: "all humans possess certain core abilities in each of the intelligences"(1993,p.28). Some individuals possess more potentials in peculiar intelligences than others, bearing in mind that some types of intelligences are prone to appear at earlier phases than others. Gardner concurs with several critics who postulated that all types of intelligences should be approached as talents(Morgan, 1992;Stage et al., 1998), whilst he affirmed that verbal and logical intelligences should be tackled equitably and not on terms of being more elevated than the remainder of intelligences(Gardner, 1993).

Learners' autonomy and diversity should always predetermine our teaching strategies in order to proffer students the momentum to learn and evolve. At this juncture, the MI theory rigorously places itself as a compatible and inclusive learning model, prone to embrace more than one cognitive model, as constructivism and flipped learning, at a time and efficiently, reaping the fruits of such productive approaches simultaneously. The implications of MI theory in higher education is that it triggered reversing the learning model from being curriculum centered into being individual learner 
centered, nourishing learners' self-esteem and individualistic dispositions, propelling them to transform into lifelong learners.

\section{Background}

Fiction( ENG 222)classes palpably find shallow appeal amongst junior students of both Translation and Linguistics programs at Prince Sultan University in Riyadh. It is the second literary course students are compelled to take after its prerequisite, Introduction to Literature (ENG 221). ENG 222 is designed to acquaint students with the genre of novel, as it first emerged in the 18th century.

At the onset, we embark on the conspicuous reasons beyond the emergence of novel late on the literary scene. Afterwards, we start to discriminate between fiction and other forms of literary genres via studying the elements of novel and its distinctive characteristics. We are then aboard on a journey through different eras starting from the rise of the novel phase in the 18th century, the 19th century(the Victorian age), and the 20th century to be capable of grasping the drastic changes that the art of novel witnessed. Enough light is also shed on the social, political, and cultural context prevalent in each era, as it undoubtedly have influenced the literary artistry dominant then. Several fictional works are tackled to represent the era they appeared in, and to analyze their multiple literary facets.

Throughout the course, students shall be well acquainted with the various elements of every novel, and be able to analyze the traits of the fictional personae, themes, motifs and symbols. Eventually, the course would compare the modern English novel to its American counterpart and further put under scrutiny a modern English novel against an American one. This is patently the sole Fiction course students come across along the whole academic plan, that's why it lends itself to be conspicuously dense.

In this connection, in order to aptly cover such over-packed curriculum, it is per se vital to have intrinsically motivated students that are ultimately aware of the indispensable worth and contribution of literature to refining their critical thinking capabilities, enriching their language reservoir, acquainting them with diversity of human characters, they are inevitably prone to confront in their real life, urging them to forge confidently their personal perspectives and leading them to be bicultural which is extremely essential for both majors, translation and linguistics. English language students are anticipated to be conspicuously well versed not merely about the linguistic sphere but also about the cultures of both languages, the mother and target language. They should additionally acknowledge how indispensable is the historical background of the successive eras, that would accordingly enable them to perceive how is literature a faithful mirror reflecting a raw slice of life as it were in each of the concerned epochs. Moreover, reading the literary text, of the assigned novels, is substantial for a thorough grasp of the distinctive characteristics of the author's writing technique, and hence, would drag them to be capable of differentiating between the substantial aspects of the writing technique of multiple authors, belonging to various eras and origins. Failure to realize and accomplish any of the aforementioned vital elements prove precarious enough to achieving the intended learning outcomes adequately.

\section{Problem of Research}

Executing the process model of curriculum(Biggs,2003),my critical reflection on the results of course exit survey, course evaluation, incessant observation of students' engagement and participation, together with the remarkably low attendance rates yielded the conclusion that literature courses students are lacking motivation and are manifestly denying the intrinsic value of studying literature, assuming it to be impertinent to their areas of specialty, translation or linguistics. They, moreover, assumed that classical output of literature are too outworn to be studied in the $21^{\text {st }}$ century; an age that is predominantly digital. Furthermore, they proved to be ultimately reluctant to read the original literary text of the curriculum novels, discerning the contemporary adaptations presented in movies to be closer to their generation and more enticing. Not to mention that their sets of mind are most active at Bloom's two lowest-order of thinking, knowledge and comprehension. The lack of critical thinking dispositions was phenomenal amongst English department students, the mater that is enormously threatening their future employability. Explicit display of higher order thinking capabilities is rendered currently as a common requirement of any workplace, as such array of skills would ensure hiring an autonomous personality, well- equipped with manifest potentials of problem solving, leadership attributes, broad spectrum of soft skills, together with an ability to engender creative options and ideas.

Duron, Limback, and Waugh(2006) stated their definition of critical thinking as "the ability to analyze and evaluate information"(p.160), while our students were often leaning on a reliable source for in-depth analysis of the novels, awaiting the instructor to supply them with model answers to whatever anticipated questions, whether in tasks or exams, the matter that manifests the lack of self confidence in their critical thinking capabilities and clear-cut reliance on sheer memorization. I frequently received from them almost blank in-class tasks, without even any exerted minimal effort to answer the critical thinking questions there.

According to Lazere:" literature is the single academic discipline that can come closest to encompassing the full range of mental traits currently considered to comprise critical thinking "(1987,p.3). In this connection, no better subject than literature can sustain my students ascending Bloom's taxonomy, smoothly reaching its epitome:

Literature-based reading has an important effect on the development of critical thinking. A reader must recognize patterns within text, fit details into these patterns, then relate them to other texts and remembered experiences.(Critical Thinking and Literature-based Reading, 1997, p. 1) 


\section{Methodology}

The status-quo should be revolutionized; reversing roles turned out to be inevitable:" Stagnant and rigid pedagogies of teaching literature would solely contribute to prolong students' revulsion to delve into literature as an academic material"(El Sherief, 2016, p.1176). The monotonous, awkwardly conventional pedagogy of lecture-giving proves itself to be by large sterile and by no means enticing as it endorses learners as dependant and passive, paying no heed to their diverse learning styles, miscellaneous reservoirs of experiences, and individual perspectives. Put on a pedestal, the instructor used to impose his cognitive domain and approaches on learners, that are accordingly compelled to take them for granted. "Per the constructivist paradigm, the teacher should cease to undertake the didactic role of lecturing, presuming to be the all-knowing personality within class boundaries"'(El Sherief, 2016, p.1172), as such tendency heralds distortion of their autonomy and the suppression of their individualistic thinking.

Initially, I was keen to engender for my students ultimately supportive nonjudgmental environment, devoid of mockery or underestimation of their poor critical thinking knowledge, otherwise the remainder of my plan won't be efficiently executed. I resorted to current teaching pedagogies that would turn literature classes to be more engaging, while considering their diverse intelligences, endeavoring to foster my students' critical thinking dispositions. Icebreakers were implemented in my classes not merely to capture students' attention but rather as an inductive element for critical and individualistic thinking. Throughout his book, Bruner repeatedly emphasized the importance of encouraging pupils' intuitive understanding as a precursor to formal understanding. He defined intuition as: "the act of grasping the meaning, significance or structure of a problem or situation without explicit reliance on the analytical apparatus of one's craft...[It is intuition that]yields hypotheses quickly, that hits on combinations of ideas before their worth is known"(Bruner, p.60). Hence, I attempted to employ icebreakers as an inspirational pillar of my fiction and drama classes. It was a tendency to prompt their intuitive thinking to collaborate positively with their critical thinking. I exposed each group's speculations to the critical analysis of all their peers.

Furthermore, grasping the undeniable efficacy of multiple intelligences theory, I incorporated it in large proportions amongst my teaching approaches, as an eminent cornerstone of flipped and autonomous learning. In one activity, I asked each of my fiction course students to undertake one of diverse tasks, that suits her preferred learning style, and be ready to present it to all her peers. Such approach will inevitably sustain their individuality of thought and reverse their mindsets into being more analytical and critical, as this type of activities entails working on the higher levels of Bloom's Taxonomy of Educational Objectives for Knowledge-Based Goals; application, analysis, synthesis, and evaluation. Presumably, some of the designed activities went further, luring some of my students into being conspicuously creative. The bunch of activities incorporated in this intervention revolve around what the learning styles theory proposed and Dunn(1995) called "Contract Activity Package", embracing versatile teaching techniques simultaneously:

\section{Activity 1:}

When tackling one of the most sophisticated novels, To the Lighthouse, my students were invited to watch an audiovisual video about a key symbol pervading the literary text of the whole novel, the lighthouse. Respecting their autonomy, they were asked to get divided into groups at their own convenience, and to subsequently ponder over the symbolic weight of the lighthouse, from an individualistic lens. It was an endeavor towards stimulating their intuitive thinking to amalgamate positively with their critical thinking dispositions, leaning on their reservoir of knowledge and personal experience.

\section{Activity 2:}

It's ultimately essential for a literature student to get exposed to the original text of any assigned literary work. Yet my students proved reluctant to read lengthy texts, not mentioning how they conspicuously refrained from getting engaged in critical analysis of the text, for lacking enough confidence in their individual critical capabilities. I promptly started to flip the classroom, asking them to work collaboratively.

In this activity, I divided the fiction class into small groups and asked them to read an assigned part of the novel. Respecting their autonomy, every group member was expected to fulfill one of four roles: summarizer, predictor, clarifier, and quotes person. Prior to this stage, I gave them clear-cut orientation to peer learning rules. I, moreover, uploaded the task guidelines on my wiki, including details that would enlighten students about the objectives of the task and the grade distribution.

I further ensured having a competent student in every group to undertake the helper role, and hence achieve scaffolding. The following session I distributed an in-class task asking about their input in addition to some Socrative and critical thinking questions to develop their autonomous thinking and reasoning skills.

\section{Activity 3:}

In an attempt to flip the classroom, together with respecting the varied learning styles of my students, I asked my students to undertake one of the following diverse tasks, that suits her preferred learning style, and be ready to present it to all her peers:

1. Design a Google- map tracing the plot events of a novel or the biography of an author.

2. Create a comic strip portraying one of the fictional personae or a specific theme.

3. Draw a sketch for one of the novel's characters.

4. Design a word cloud epitomizing the core themes of the novel. 
5. Forge a script for new ending of the novel.

6. Create Cartoon strips for 3 master scenes in the novel.

7. Role play: introducing the protagonist through dialogue between him/her and contrary character from another literary work, or a renowned figure, or the student herself,........)

8. Selecting and performing a song reflecting the era.

\subsection{End of Course Project}

The end of course project was palpably challenging, as it was deliberately designed to assign students the leader's role.Via this project, students were propelled to dig for an innovative format of presenting one of the plays or novels as a one-act play on the stage of the large auditorium of PSU, by the end of the semester, in front of the massive community of PSU students and faculty. They were compelled to capture a creative perspective, from which to convey the core of the original play, undertake writing the whole script, and eventually to perform their own modernized version on the stage. Henceforth, they were divided into four groups, script, setting, acting, and stage direction(according to their areas of interest).

Through this qualitative study data was garnered through end of course questionnaire with diverse open-ended questions to let participants follow their own paths and describe meticulously the pros and cons of their experience. Close observation of students' contribution, performance, output, and their responses to the challenging critical thinking questions in major exams and final exam were scrutinized. Formative and summative assessment were both involved, together with a holistic rubric paying enough heed to creativity, prudence, and resourcefulness.

\section{Results and Discussion}

The core thesis of the present action research postulated that designing projects, revering our students' multiple intelligences and varied potentialities would inevitably trigger enhancing their engagement, their individualistic dispositions, and critical thinking. What has been observed throughout the intervention proved that multiple intelligences projects served enormously to flip the classroom and reverse roles, a momentum that facilitated autonomous learning in a superbly smooth way. At the very beginning of the intervention students were apprehending the fact that the whole learning process will be carried out by students vis-a-vis the traditional method of one-way transmission of knowledge, having the teacher at the very centre of it. I gradually realized that the reason beyond such horror is their lack of confidence in their potentials and critical thinking capabilities. Thus, the nonjudgmental ambiance, devoid of mocking or underestimation, substantiated their self confidence and served dissolving the inertia. I was incessantly affirming that in literature, all arguments are accepted provided that they are corroborated with reliable supports and evidences. Conveying to my students the fact that there is no true or false answer boosted confidence in their individualistic thinking, and prompted them to be assertive to evince their individual input. Gradual improvement started to be explicit to the naked eyes. Ascending social rapport and camaraderie, palpably active interpersonal and personal skills, persistence to transcend barriers and find out of the box solutions to emerging problems and challenges, positive responses to Socrative questions merged within the in-class tasks, being assertive about their personal perspectives and thoroughly capable of supporting them with enough evidences, the ultimately innovative layouts and presentations, the creative answers remarks and commentaries, the noticeable potential of relating remote eras to their mundane life, autonomous learning abilities, individualization, inquiry seeking instead of the stereotype pattern of sheer memorization, served all as undeniable tokens of the recently cultivated soft skills and individualistic dispositions, in addition to corroborating by far the efficacy of MI as a project- based approach.

Moreover, Dunn's "Contract Activity Package" sustained me to present literature as an enticing material, contrary to the stereotype image rendered by students about classical literature. Throughout the intervention, the incorporation of audio-visual technology package(Google-maps, You Tube videos, movies, songs, prezis, gallery walks, word clouds, and icebreakers )proved to be the most adequate to act in parallel with the multiple intelligences projects in order to augment engagement. The first activity served as a stone thrown into the stagnant lake, as it addressed various learning styles, serving as a stimulus to students' intuitive thinking. Listening to the song, accompanied by the lighthouse scenes, was followed by an inductive discussion about the significance of this symbol and why does it reverberate throughout the novel. It was one of the most appealing activities that was employed as a prologue to an in-depth delving within the novel and its innovative technique. Bruner (1996) emphasized that when a teacher prompts his students' guessing and intuitive thinking and exposes such input to the critical analysis of their peers, he is par excellence urging them to be more assertive about their individualistic thinking instead of succumbing to being dependant on the teacher to acquire knowledge.(p.93)

Furthermore, the second activity accomplished versatile objectives as the majority of students led the experience of reading the original text, fulfilled their roles, whether summarizing or commentating on events, and also inserted their input about what they read, which started to work as an impetus for their critical thinking skills to cross the boundaries. Relatively small proportion of students came to class totally unprepared, leaning on explanatory notes to substantiate for the original text of the novel. I further noticed that misunderstanding and confusion are liable to happen. So the teacher can never be exempted from the scene. Adopting the role of the facilitator, I was compelled to ensure students that I am sustaining them whenever needed. I was walking by each group, monitoring their answers to spot misconceptions and gaps in understanding, posing further questions that would guide them to the targeted information. By the end of such 
task, I realized it was the ideal solution to several problems as it led them to read the original text of the novel, substantiated their confidence in their critical knowledge and promoted it. Every student approached the text from an ultimately different perspective than her peers. Sharing such diverse interpretations contributed to enriching the overall learning outcomes of sessions."The shift from simple thinking to higher order and more abstract thinking, moving from the surface level to the strategic and on to the deep level, and from declarative knowledge into the procedural and conditional; and the completion of the loop, the joining of the circle, the acceleration of the dynamic spiral, for both helpers and helped"(p.639) .

A trusting relationship with a peer, proving to have no authority, would virtually trigger unveiling weaknesses and misconceptions, and hence paving the path for diagnosis and correction (Topping 2005).As for the helper student, the one fulfilling the scaffolding role, a participant is at times able to grasp the concept or rather gaps in understanding such concept only when compelled to explain it to others(Vygotsky). It's the teacher's role then to bridge those gaps if there is any. For instance, I discovered that few students misinterpreted some of the fictional personae or didn't absorb some pivotal information. I started to refute their invalid arguments and correct the unreliable information. Students, in return, revealed apparent interaction. Eventually, the helper and helped have collaborated to enrich each other's declarative knowledge, procedural skills, "extending current capabilities ( accretion), modifying current capabilities(re-tuning), rebuilding new understanding(restructuring)"(Topping,2005, p.637). Such pedagogy helped disseminating engaging airs while still meeting the whole learning objectives.

As for activity 3, during class time students were anticipated to present their work in front of their peers, being open to questions from my part and their peers. It was an innovative way to expose the fictional elements as plot, themes, characters via individualized lenses and frames. Instead of narrating the series of events in a traditional way, a Google map said it all in a more attention- grabbing way. A sketch was the most inviting induction into an in-depth analytical account of one of the fictional personae. When exhibiting her sketch, I attempted to ask the student, for instance, about the reasons beyond the choice of colors, shades, background, and dimensions to urge her to unravel for her peers all key facts relevant to the character's portrait in the novel. I didn't expect anyone to go for the sketch activity, yet I astonishingly discovered that some very talented students took it explicitly seriously. Unexpectedly, a group has written a script for a confrontation scene between two contradictory heroines belonging to two different novels, unveiling their contradictory approaches towards life and the patriarchal figures in their lives. Another student forged a controversial dialogue between herself and a protagonist, poignantly critiquing her ideologies and pondering profoundly over current life dilemmas. Giving vent to students' potentials and talents to act beyond boundaries propelled them to prolong enough within the literary text to be able to present it admirably through their individual perspectives, the matter that fostered their logical reasoning, synthesis and argumentation abilities, problem-solving, inference and analysis skills, evaluation and application, deductive and inductive reasoning. The ambiance turned out to be fraught with enticing airs instead of the traditional vision of literature as a rigid material.

The bunch of such micro projects paved the path for the macro project(end of course project) that was a solid and decisive challenge to my students' critical thinking abilities and individualistic approaches in addition to its being an objective qualitative assessment of the potential of the deployed MI strategy. Recreating a classical literary work according to their personal vision, undertaking the whole performance process from scratch was a crucial test of the total improvement accomplished with regard to their autonomous dispositions and critical thinking skills. They chose to change the setting to be a Saudi locale, instead of the original Scandinavian one, modifying the plot events, climax, denouement, ending, characters' approaches and responses, even props and costumes were totally revolutionized to suit the culture and milieu presented. They created ghost characters to work as commentators on events. I was vastly impressed by their genuine creativity; the recently-acquired capability to deconstruct the elements of literary work, reconstructing them as pertinent to their ideologies and perspectives.

Furthermore, observing my students performance in summative exams was an additional quasi-qualitative way of evaluating the validity of the deployed approach. I attempted to redesign my summative exams to include both objective and subjective questions. While objective questions were meant to measure the student's adequate grasp of the course material and to ensure that all learning objectives are accomplished, subjective questions, on the other hand, were created to assess the efficiency of the teaching approach I applied with my students, that was geared towards improving their critical thinking capabilities. Subjective questions in my literature exams were testing the development of my students' critical thinking knowledge and problem-solving skills. Exams incorporated ultimately higher-order critical questions, asking them to apply a current critical theory(e.g. political ecology, post-colonialism) to one of the studied novels. The majority of questions were genuine questions relying on the student's approach and perspective in comparing and contrasting certain fictional characters, relating some of the novel's dimensions to the historical backgrounds, or rather analyzing the essence of two novels against a certain renowned proverb. My students proved to be comfortable with all these subjective questions and I was bragging about receiving very creative and solid hypotheses through my students' answers, the matter that corroborates the validity of all the teaching pedagogies employed to enhance their critical knowledge and to consolidate their confidence in their autonomous thinking.

\section{Conclusion and Implications}

This action research was engendered by the problem I faced with PSU students as for the lack of motivation in prolonged studies of literary subjects and the explicit reluctance to employ their critical thinking capabilities for the lack of confidence in their critical knowledge. At this juncture, and in order to be capable of meeting all the intended learning outcomes and CLOs of the literary subjects, it was ultimately crucial to have motivated students that do grasp 
the undeniable worth of literature and its ability to foster their critical thinking capabilities, deepen their domain of language, presenting them to a long array of human characters, they might encounter in their real life, urging them to form their personal ideologies and leading them to grow into autonomous learners, which is essential to both majors, translation and linguistics. Evolving into being bi-cultural is a further merit to be discerned, as English language students are anticipated to be conspicuously well versed not merely about linguistics or translation but also about the cultural background of both mother and target languages. They should additionally realize how vital is the historical background of the successive eras. In-depth delving into the literary text, of the assigned novels, is indispensable for a thorough grasp of the distinctive aspects of the author's writing technique, and deep analysis of the multiple literary pillars. The lack of any of the aforementioned vital elements prove perilous enough to meeting the course objectives adequately.

Moreover, our students lacked the individualistic trend of thinking, that is principally engendered via critical thinking dispositions, the matter that seriously threaten their future employability. Literature is profoundly promising of fostering students' critical thinking capabilities for being over-packed with denotation, connotation, multi-layered text and implicit meanings, deciphering information, connecting scattered signals to capture inferences and form synthesis, reconstruction of dispersed information to create in mind accurate portrait of the multiple characters, analyzing the text against the mainstreams and phenomena of the historical epoch then.

Multiple Intelligences activities(role playing, Google-maps, sketches ,...etc), collaborative tasks, flipped classroom, inclass tasks based on Socratic questions and logical reasoning, inspirational ice-breakers, and gallery walks were incorporated in large proportion and proved influential in liberating students from cemented frames of traditional learning into broader spheres of critical dispositions and individualistic thought, and conspicuously polished soft skills. Such bunch of activities propelled students to execute their individualistic dispositions assertively and in a highly appealing way. They were employing the literary text as a raw material from which they could engender their very impressive and creative individual layouts, evincing their diverse areas of interest. The positive applaud they received from their peers as well as the instructor boosted their self assertion about their individualistic capacities, as numerous students came up with patently creative output that was beyond expectations. The incorporation of technology helped bridging the gap between the instructor and the student. Hence, even critical thinking activities were mostly relying on technology, in order to make them more current.

Throughout the intervention, I was keen to sustain my students, nurturing their self assertion even in exams. I recurrently assured them that all arguments are accepted as long as you are able to corroborate them with enough supports. The matter that resulted in explicitly distinctive worthwhile answers, manifesting the lately acquired high order of critical thinking. Exams incorporated ultimately higher-order critical thinking questions, asking them to apply a current critical theory(e.g. political ecology, post-colonialism), for instance, to one of the studied novels. The final exam answers proved par excellence my students' capacities to confidently form individualistic hypothesis and elect the solid supports to corroborate its validity. When given enough room and confidence to implement their critical thinking skills they impressed me as an instructor with vastly creative answers, the matter that was by all means preposterous in the near past.

Eventually, The end of course project proved my students' progress in all soft skills, as they were fraught with the thorough responsibilities of initiating and presenting a dramatic performance; being assigned all the roles with respect to their areas of interest: authoring, directing, costumes, acting, logistics, ....etc. They were capable of forging their own version of the script, creating new setting; modified the opening and ending to suit such new context. They, moreover, created ghost characters to act as commentators on events. Noticeable acclaim was received in recognition of their impressive contribution from audience, other faculty, and instructor. Their outstanding creativity, enthusiasm, and potency eventually emphasized the efficacy of the current plan of action.

\section{References}

Barrington, E. (2004). Teaching to Student diversity in Higher Education: How Multiple Intelligences Theory Can Help. Teaching in Higher Education,9(4),421-434.

Biggs, J. (2003). Teaching for Quality Learning at University. Buckingham: The Society for Research into Higher Education and Open.

Bishop, J.L. \& Verlager, M.A. (2013). The Flipped Classroom: A Survey of the Research. 120th ASEE Annual Conference \& Exposition. http://www.studiesuccesho.nl/wpcontent/uploads/2014/04/flipped-classroom-artikel.pdf

Bloom, B., Englehart, M, Furst, E., Hill,W. \& Krahtwohl, D(1956). Taxonomy of Educational Objectives: The Classification of Educational Goals. Handbook 1: Cognitive Domain. New York: Longmans Green.

Bruner, J. (1996). The culture of education. Cambridge, MA: Harvard

University Press.

Campbell, L., Campbell, B.\& Dickinson, D.(1996) Teaching and Learning through Multiple Intelligences(Boston, MA, Allyn\& Bacon).

Chapman, A.(2009, December 20). Howard Gardner's Multiple Intelligences. Retrieved January18th,2016, from businessballs.com: http://www.businessballs.com/howardgardnermultipleintelligences.htm. 
Critical Thinking and Literature-Based Reading(1997). Report. Madison, WI: The Institute for Academic Excellence. Retrieved from http://www.eric.ed.gov/ERICWebPortal/custom/portlets/recordDetails/detailmini.jsp?_nfpb=true\&_\&ERICExtSearch_ SearchValue_0=ED421688\&ERICExtSear ch_SearchType_0=no\&accno=ED421688

Dunn, R., Griggs, S. A., Olson, J., Gorman, B., \& Beasley, M. (1995). A meta analytic validation of the Dunn and Dunn learning styles model. Journal of Educational Research, 88(6), 353-361.

Dunn R, Dunn K(1993). Teaching Secondary Students through Their Individual Learning Styles: Practical Approaches for Grades 7-12. Boston: Allyn \& Bacon.

Duron, R., Limbach, B., \& Waugh, W. (2006). Critical thinking framework for any discipline. International Journal of Teaching and Learning in Higher Education, 17(2), 160-166.

Elsherief, E. (2016). Forth to the Past: Digitizing Literature Classes. In Proceedings of EdMedia: World Conference on Educational Media and Technology 2016 (pp. 1172-1176). Association for the Advancement of Computing in Education (AACE).

Felder, R. M., \&Brent, R.(2005). Understanding Student Differences. Journal of Engineering Education,94(1).

Gardner, H.(1983). Frames of Mind: the Theory of Multiple Intelligences(New York, Basic books).

Gardner, H.(1993). Multiple Intelligences, the Theory and Practice(USA, Harper Collins).

Gitsaki, C., Robby, M.A., Priest, T., Hamdan, K., \& Ben-Chabane, T. (2013). A research agenda for the UAE iPad initiative. Learning and Teaching in Higher Education: Gulf Perspectives 10(2), 1-15.

Lazere, D(1987). "Critical Thinking in College English Studies," ERIC Digest. ED 284275. Retrieved from http://www.eric.ed.gov/ERICWebPortal/con tentdelivery/servlet/ERICServlet?accno=ED284275

Lazerson, M., Wagner, U. \& Shumanis, N. (2000). What makes a revolution? Teaching and learning in higher education, 1980-2000. Change, 32(3), 13-19.

Oermann, M. H. (2004). Using active learning in lecture: Best of "both worlds." Journal of Nursing Education Scholarship, 1(1), 1-11. Available at http://www.bepress.com/ijnes/vol1/iss1/art1

Thurstone, L. L. (1938). Primary mental abilities(Chicago, IL, Chicago University Press).

Tobin, K., \& Tippins, D. (1993). Constructivism as a referent for teaching and learning. In K. Tobin (Ed.), The practice of constructivism in science education. Washington: AAAS Press.

Topping, Keith J. (2005). Trends in Peer Learning. Educational Psychology,25(6),pp.631-645.

UNESCO (2001)Report on World Conference on Higher Education. Available online at: http://www.unesco.org/education/wche/index.shtml (accessed 26 February 2004).

Vygotsky, L. S. (1978). Mind in society: The development of higher psychological processes. Cambridge, Mass.: Harvard University Press.

\section{Appendices:}

Samples of students' activities:

Google-map(Plot overview)

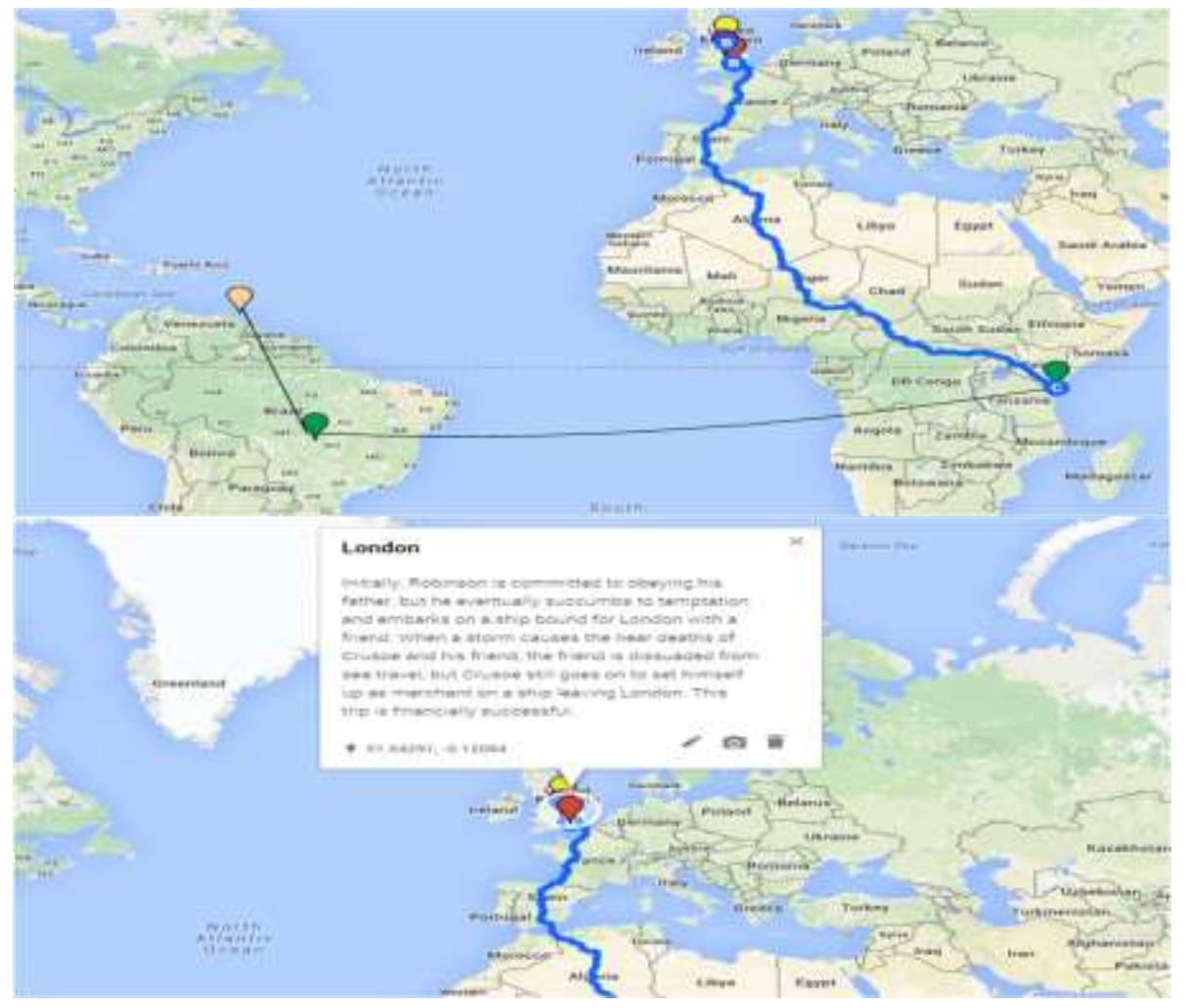


Word Cloud (themes-symbols-motifs)

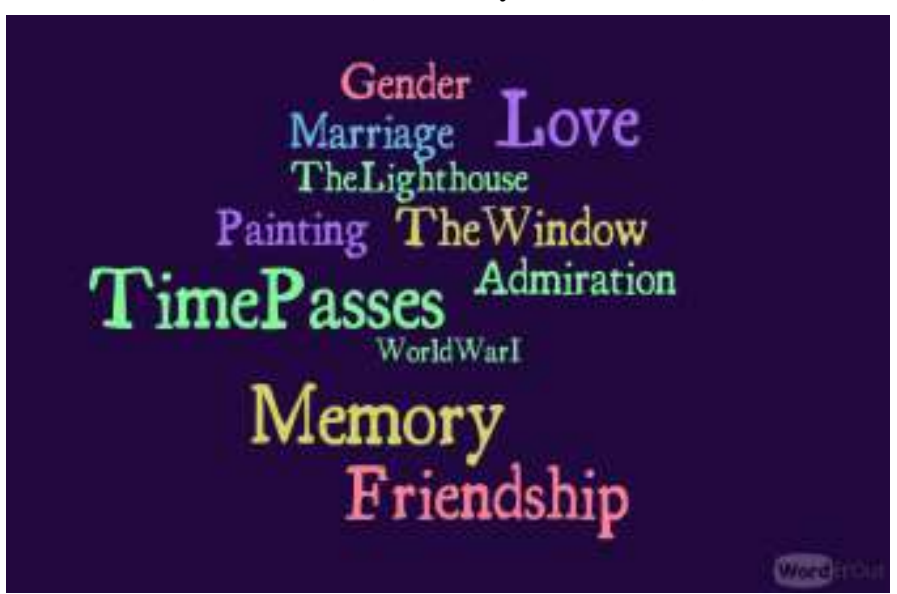

Sketch (Character Analysis)

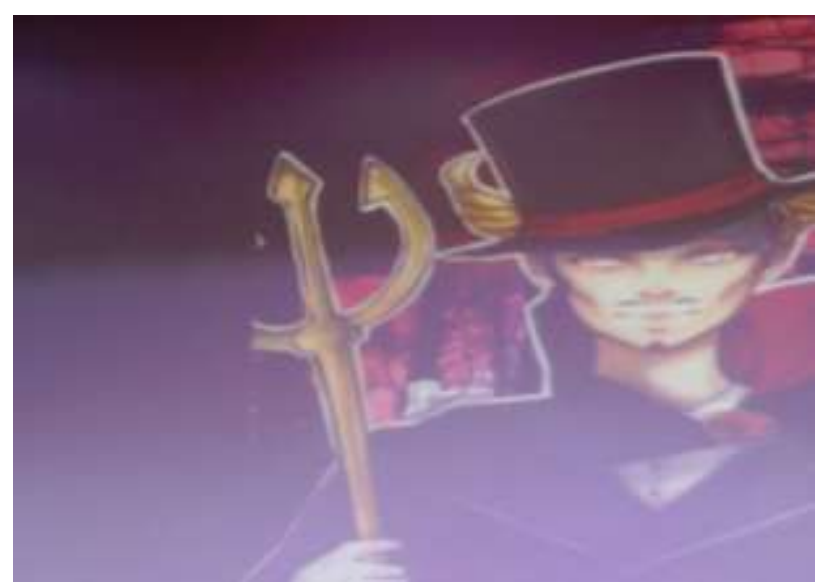

End of Course Project: One- act Play

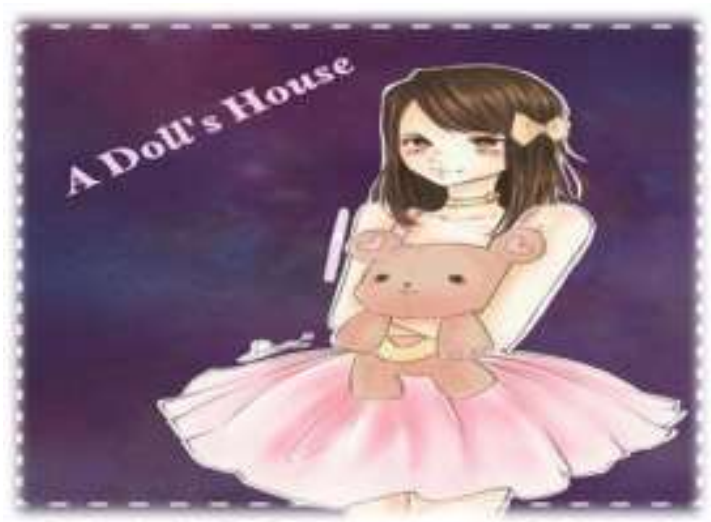

